Article

\title{
Optical Trapping, Sizing, and Probing Acoustic Modes of a Small Virus
}

\author{
Jeffrey Burkhartsmeyer ${ }^{1}$, Yanhong Wang ${ }^{2,3}$, Kam Sing Wong ${ }^{1}$ and Reuven Gordon ${ }^{4, *}$ \\ 1 Department of Physics, Hong Kong University of Science and Technology, Clear Water Bay, Kowloon, Hong \\ Kong, China; jmb@connect.ust.hk (J.B.); phkswong@ust.hk (K.S.W.) \\ 2 School of Information and Communication Engineering, North University of China, No.3 Xueyuan Rd, \\ Taiyuan 030051, China; wangyanhong@nuc.edu.cn \\ 3 Academy for Advanced Interdisciplinary Research, North University of China, No.3 Xueyuan Rd, Taiyuan \\ 030051, China \\ 4 Department of Electrical and Computer Engineering, University of Victoria, P.O. Box 3055 STN CSC, \\ Victoria, BC V8W 3P6, Canada \\ * Correspondence: rgordon@uvic.ca
}

Received: 27 November 2019; Accepted: 1 January 2020; Published: 4 January 2020

Featured Application: Sizing and measurement of vibrational frequencies of viruses could be useful for diagnostic purposes, as well as for targeted destruction via resonant excitation of virus particles.

\begin{abstract}
Prior opto-mechanical techniques to measure vibrational frequencies of viruses work on large ensembles of particles, whereas, in this work, individually trapped viral particles were studied. Double nanohole $(\mathrm{DNH})$ apertures in a gold film were used to achieve optical trapping of one of the smallest virus particles yet reported, PhiX174, which has a diameter of $25 \mathrm{~nm}$. When a laser was focused onto these DNH apertures, it created high local fields due to plasmonic enhancement, which allowed stable trapping of small particles for prolonged periods at low powers. Two techniques were performed to characterize the virus particles. The particles were sized via an established autocorrelation analysis technique, and the acoustic modes were probed using the extraordinary acoustic Raman (EAR) method. The size of the trapped particle was determined to be $25 \pm 3.8 \mathrm{~nm}$, which is in good agreement with the established diameter of PhiX174. A peak in the EAR signal was observed at $32 \mathrm{GHz}$, which fits well with the predicted value from elastic theory.
\end{abstract}

Keywords: optical trapping; virus; elastic properties; acoustics; GHz ultrasonics; optics; Raman

\section{Introduction}

Optical tweezers are under development since Ashkin's seminal work, first reported in 1970 [1]. Optical trapping since burgeoned into a wide field ranging from studies on micron- and nanometer-scale biological systems, to fundamental physics of ultra-cold ions and atoms [1-27], as well as advanced methods to manipulate nanometer-scale materials such as via holographic optical tweezers [28-31]. While viruses were trapped before by optical tweezers, this was only for the largest viruses that are extremely elongated and, thus, easier to trap (e.g., Tobacco Mosaic Virus) [2], or just large (HIV) [3]. To stably trap smaller viruses with reasonable power, it is necessary to make use of field enhancement via plasmonic effects from nanostructures [4]. This is because simple optical tweezers take advantage of an intrinsic gradient force within the focus of a laser beam, due to the variation in intensity from beam waist to center. This is limited to a size scale on the order of hundreds of nanometers, due to the diffraction limit. 
In contrast, plasmonic trapping takes advantage of local field enhancement in the vicinity of nanometer structured metals $[3,11-20]$ and, thus, can overcome the diffraction limit. One such scheme is to create nanometer-scale apertures in metals, and to focus the trapping laser onto these apertures [3,5-11,17-22,27]. In particular, double nanohole (DNH) apertures were developed which create extremely high local field strengths in the area in between opposing sharp edges where the two holes meet. In this work, such DNH apertures are found to enable the trapping of one of the smallest virus particles reported, at powers low enough to leave the virus particles intact for several hours of experiment time. As a demonstration of possibilities to characterize individually trapped virus particles, two techniques were performed in this work. The particles were sized via an established autocorrelation analysis technique [5-8], and the acoustic modes were probed using an extraordinary acoustic Raman (EAR) method [9,10,22].

When a particle is trapped, it is subject to a gradient force field which tends to move it toward the position of a potential minimum. Due to Brownian motion, the particle will undergo random displacements. The restoring force from the optical trap is akin to that of a spring, proportional to the displacement to a first-order approximation. There is also drag due to the surrounding media, which is proportional to the radius of a spherical particle, to first order. If the restoring force of the optical trap is sufficient to overcome these thermally driven movements, the particle will remain within the trap and the displacements of the position will manifest as variations in the transmission signal. Analysis on these variations can be used to characterize both the trap stiffness and the particle diameter [5-8]. Details of this analysis are covered in Section 2.

Determination of elastic properties and, in particular, vibrational frequencies of viral structures is much sought after [32-48]. Characteristic frequencies can be used as a "fingerprint" to identify viruses. It was also proposed to resonantly excite viruses to selectively destroy them, while leaving the surrounding material undisturbed as a potential method of treatment of disease [49-52]. This study demonstrates an easily implemented technique to directly measure the frequencies of acoustic modes of very small individual virus particles for the purpose of a fundamental understanding of their biophysics, diagnostics, or targeted destruction of the contagion. The advantage of the technique used here to determine the vibrational frequencies is that individual, optically trapped particles can be probed, and the frequency regime in the $\mathrm{GHz}$ is accessible. Prior to the development of the EAR technique $[9,10,22]$, opto-mechanical methods for measuring mechanical vibrations were limited to a range of frequencies above $100 \mathrm{GHz}$ for the case of traditional Raman scattering [42,53], and sub-gigahertz for cavity resonator-based approaches [54]. This left a gap of the important GHz range, where characteristic frequencies of structures of nanometer size scale should be found, according to elastic theory [37-42,55-58]. Viruses are of nanometer size scale and, thus, predicted to have vibrational modes in the $\mathrm{GHz}$ frequency range. Brillouin scattering can probe the $\mathrm{GHz}$ frequency range and, indeed, some Brillouin studies were done on viruses $[43,46,48,59,60]$; however, the peaks were difficult to observe possibly due to damping by water or core-shell interactions, as discussed in those works. Moreover, unlike these other opto-mechanical measurement methods, the EAR technique provides a high resolution of vibrational frequencies of individual nanometer-scale particles which are confined by optical trapping, as opposed to measuring ensembles of particles in the case of Raman and Brillouin scattering studies. This technique also has the advantage of directly measuring low-wavenumber Raman active modes of single trapped particles, while avoiding the issue of Rayleigh scatter overwhelming the signal near the zero-loss line, as is the case for traditional elastic light scattering spectroscopy.

Previous work using the extraordinary acoustic Raman (EAR) technique investigated small proteins including DNA and polystyrene nanospheres [9-11,22], whereas here we report of the study of a virus using the technique, since the vibrational frequencies of viruses were of interest to researchers for some time [35,37,38,40-48,60-67]. The EAR technique involves the application of two lasers. Both lasers are focused on an aperture, forming an aperture-assisted laser tweezer, in which a small particle is trapped. The interference of the two lasers at slightly different wavelengths creates a "beating" oscillation in the electric field which then causes a stretching force on the trapped particle through 
electrostriction. The frequency of this oscillation is controlled by the difference in wavelength of the two lasers. The wavelength of one laser is held fixed, while the other is swept through a wavelength range differing from the fixed-wavelength laser by sub-Angstrom to nanometer values, corresponding to beat frequencies in the $\mathrm{GHz}$ range. When the frequency of the beating oscillation produced by the interfering lasers matches the frequency of an acoustic mode of a trapped particle, there is stronger interaction of the electric field with the structure, leading to an increase in the movement of the particle within the trap. The laser transmission through the aperture depends on the position and conformation of the particle within the aperture and, thus, an increase in movement of the particle is observable as an increase in the fluctuations of the transmission signal. It is this variation of fluctuations of laser transmission signal that is detected for the EAR measurement.

The previous EAR studies of nanometer-scale particles found peak frequencies which matched well with predicted values from elastic theory. In this work, the bacteriophage PhiX174 was studied-chosen for its small size, low biological safety rating, and history of being extensively studied. It makes a good model system for icosahedral viruses, of which there are many [68-70], although the techniques used here could be extended to the study of viruses of other size and shape. The size and morphology of PhiX174 is well established from SEM studies and crystallography [71-74]. PhiX174 is a coliphage which infects Escherichia coli bacteria [75]. Detection of such viruses can indicate the presence of fecal matter in aquatic environments [76].

\section{Materials and Methods}

\subsection{Optical Trapping Set-Up}

A modified Thorlabs OTKB Modular Optical Tweezers System was used for the optical trapping experiments (Figure ??a). Two Thorlabs DBR852P lasers were each passed through an optical isolator to prevent back-reflections from the microscope set-up and feedback from the other laser. The output laser light from the optical isolators was then introduced to the set-up via a 50/50 fiber coupler, one output of which was connected to a fiber launcher at the input of the microscope cage set-up. The other output of the 50/50 fiber coupler was sent to an optical spectrum analyzer in order to determine the wavelengths of the lasers for the interference beat frequency computation. The combined laser light is focused down onto a single $\mathrm{DNH}$ aperture via the $100 \times$ microscope objective, and the transmission is collected and collimated via the $10 \times$ objective. This transmission light is measured by an avalanche photodiode (APD), after first being attenuated by an optical density filter as required to bring the intensity level down to the measurable range of the APD.

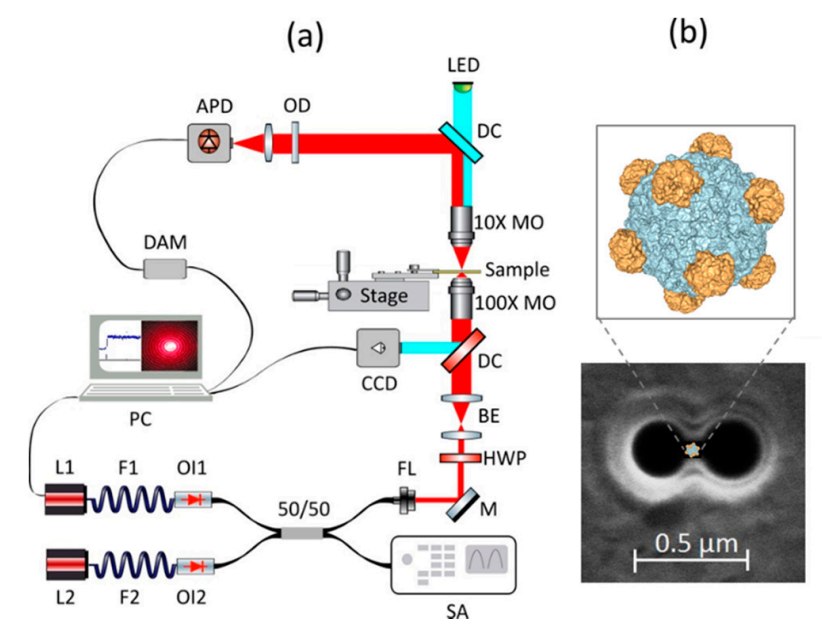

(b)

Figure 1. (a) Experimental set-up-(L1) tunable laser, (L2) fixed laser, (F1 and F2) optical fibers, (OI1 and OI2) optical isolators, (50/50) fiber coupler, (FL) fiber launcher, (SA) spectrum analyzer, (M) mirror, 
(HWP) half wave plate, (BE) beam expander, (DC) dichroic mirror, (CCD) charge-coupled device camera, $(10 \times$ and $100 \times \mathrm{MO})$ microscope objectives, (LED) white light source, (OD) optical density filter, (APD) avalanche photo diode detector, (DAM) data acquisition module, (PC) personal computer. (b) Focused ion beam (FIB) image of the double nanohole (DNH) aperture with schematic of PhiX174 inserted.

\subsection{Sample Preparation}

The DNH aperture structures were milled into a 100-nm gold slide using a focused ion beam (FIB), with a distance of $40 \mathrm{~nm}$ between the points where the circles meet (Figure ??b). An adhesive slide spacer (Grace Bio-labs GBL654002) was affixed to the gold slide, and $10 \mu \mathrm{L}$ of fluid containing the nanoparticles to be studied was dropped into the gap in the spacer. A glass cover slide was then affixed on top of the slide spacer. The sample was placed with the cover slide face down into the optical trapping set-up, with a small amount of immersion oil between the slide and the $100 \times$ objective, used to both focus the laser down onto the DNH apertures and image a white-light transmission through the aperture and the back-reflected laser spot via the charge-coupled device (CCD).

\subsection{Sizing}

Trapping experiments were performed on two sizes of commercial polystyrene spheres (Thermo Fisher Scientific Nanosphere $22 \pm 2 \mathrm{~nm}$ and $31 \pm 3 \mathrm{~nm}$ ) and PhiX174 coliphage virus sample (Carolina 124425 at $10^{10}$ plaque-forming units/mL). Virus sample was purified via filtration (VWR International $0.2-\mu \mathrm{m}$ cellulose acetate sterile syringe filter) and centrifuged at an estimated $30,000 \times g$ [77] for $15 \mathrm{~min}$, before the supernatant was removed. For full details of the sizing technique, see past studies $[3,23,27]$. Each type of sample was trapped multiple times, and autocorrelation of the transmission signal after trapping was calculated. The characteristic time, $\tau 2$, was extracted by fitting the autocorrelation curve to a double exponential. For this analysis, the particles are taken to be spherical. Since the radius of the particle is comparable to half the distance between two walls of the aperture in the trapping region, only the first-order terms are taken to calculate the Stokes drag coefficient via Faxen's Law. This leads to a simple linear dependence between Stokes drag coefficient and the particle radius. This implies that the time constant, $\tau 2$, is directly proportional to the radius of trapped spherical particles as well. For each type of sample, the average of the computed $\tau 2$ value was taken over the multiple trapping events. Finally, this averaged $\tau 2$ of was plotted against particle size, and fit to a line.

\section{4. $E A R$}

The two lasers, each with a power of $10 \mathrm{~mW}$ as measured at the fiber launcher input to the trapping set-up, were turned on to trap the particles. The two lasers were tuned to the same wavelength of $853.08 \mathrm{~nm}$ during trapping, so that any beating due to interference would be of low frequency so as not to disturb the trapping process. Virus and polystyrene spheres were each trapped multiple times across many days. After trapping a particle, one laser was held fixed at $853.084 \mathrm{~nm}$ wavelength, while the other was tuned over a range of 853.273 to $853.084 \mathrm{~nm}$, by varying the temperature via the controller, with an automated Matlab process. Each step was $0.01 \mathrm{~K}$, corresponding to a $\sim 0.001-\mathrm{nm}$ wavelength change, as measured by the optical spectrum analyzer. For each wavelength step, the signal of the APD was accumulated for $15 \mathrm{~s}$ at $5 \mathrm{kHz}$ acquisition frequency via a (Labjack U3-LV) data acquisition module. The normalized standard deviation of the APD signal was computed for each wavelength step. This measure of noise level increases as the beat frequency of the interfering lasers approaches the characteristic frequency of the trapped particle, which shows up as a peak in the noise level of the signal at the resonance value.

As a simple model to predict the resonance frequencies of PhiX174, Lamb's theory [55-58] was used. The icosahedral geometry of the virus studied in this work, PhiX174, can be simplified further by taking it to be a sphere. Despite much discussion and study on the elastic properties of viruses in existing literature, the wave speeds of viruses are generally not well established. Consistent with best estimates from previous works [43,44,47], for PhiX174, the longitudinal wave speed and Poisson's 
ratio were here taken to be $\sim 1800 \mathrm{~m} / \mathrm{s}$ and $\sim 0.3$ (corresponding to a transverse wave speed of $900 \mathrm{~m} / \mathrm{s}$ ), respectively. Using these values, the frequencies of the L0 mode were calculated to be $30 \mathrm{GHz}$.

\section{Results}

Polystyrene nanospheres and PhiX174 bacteriophage were separately optically trapped, all in the same DNH aperture in a gold film. Figure 2a shows the laser transmission signal as measured at the APD during a trapping event, with a characteristic jump in voltage, as well as an increase in the noise level. The autocorrelation of the signal after the trapping event was computed and fitted to a double exponential to extract the characteristic time, as shown in Figure $2 b$. The averaged characteristic time for each of the sample types is plotted against the known radius of the particles in Figure 2c, showing a good linear fit. This justifies the assumptions used in the Stokes coefficient calculation, i.e., spherical particles, far from the aperture walls.

(a)

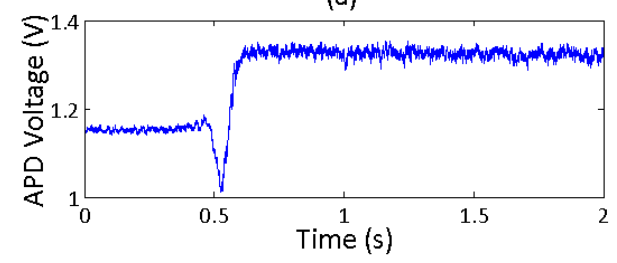

(c)

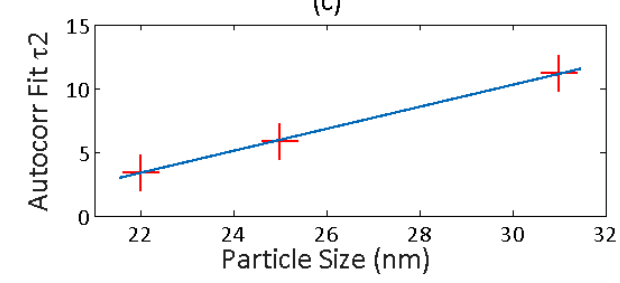

(b)

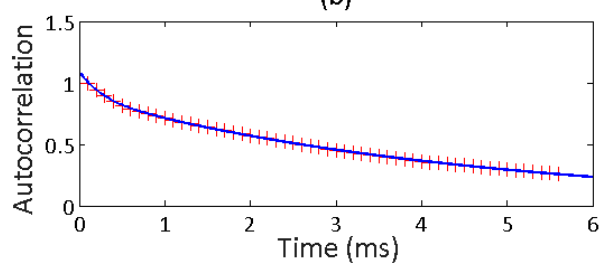

(d)

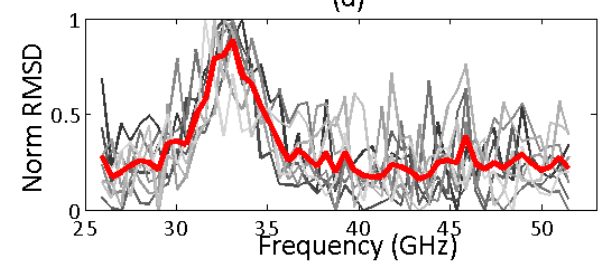

Figure 2. Sizing of particles via autocorrelation analysis: (a) a typical signal of a trap event; (b) autocorrelation of the signal after trapping, with double-exponential fit curve to extract the time constant, $\tau 2$; (c) a linear fit of the values of the time constant obtained from the autocorrelation curve fit, $\tau 2$ vs. particle diameter for the three particle sizes; (d) eight measurements of the extraordinary acoustic Raman (EAR) signal of PhiX174 virus, along with the averaged curve in red, showing a peak at $32 \mathrm{GHz}$.

For the EAR study, polystyrene spheres were used as a control, with results matching previous EAR studies [9-11,22]. We also applied this technique to another bacteriophage, MS2, but it is not reported here. For each sample type, consistent peaks were observed across multiple trapping events. The EAR spectrum of the PhiX174 bacteriophage from eight separate measurements taken over two days is shown in Figure 2d, with a peak at $32 \mathrm{GHz}$. This differs slightly from the predicted value from elastic theory of $30 \mathrm{GHz}$. This difference may be partly attributable to the simplification in the model of the icosahedral geometry to that of a sphere or to the estimation of values of the wave speeds in the virus structure.

\section{Discussion}

It is well established that optical trapping enables the performance of experiments on single nanometer-scale particles. While the possibility to optically trap large viruses existed for decades, trapping with the aid of DNH apertures of one of the smallest viruses yet reported was demonstrated here. We showed the feasibility of identifying the virus in question, by determining the size of the particle, as well as experimentally measuring the signature acoustic modes. Such identification experiments, along with others such as standard Raman spectroscopy [78-81], could be useful for diagnostic purposes or for virus particle sorting. 
The sizing technique, which models the optical trap as an overdamped harmonic oscillator, relies on some simplifying assumptions, i.e., that the particle is spherical, and that the particle radius is small compared to the distance between the aperture walls. PhiX174 has an icosahedral geometry, which is nearly spherical, with an established diameter of $25 \mathrm{~nm}$, while the distance between aperture walls is $40 \mathrm{~nm}$; thus, these assumptions are reasonable. Moreover, when the radius of a trapped PhiX174 particle along with those of two polystyrene sphere sizing standards was plotted against the characteristic times extracted from the experimental data, a good linear fit was found, which seems to justify those assumptions. It also helps to give confidence that the trapped particles were the expected ones, instead of some contaminant, which is always a possibility when it comes to trapping nanometer scale particles in liquids.

One potential concern could be the effect of temperature on the optical experiments. Temperature could affect the physical attributes of the material being measured, such as acoustic properties or conformation of the structures, as well as affecting the measurement system itself; for example, transmission of the laser through the $\mathrm{DNH}$ aperture is likely temperature-dependent. The sample was not actively cooled; however, DNH apertures were in a gold substrate with a large surface area, which should transmit heat away from the sample area inside the DNH aperture, at the focus of the lasers. While it would be difficult to measure the local temperature at the sample, which is held within the focus of the lasers, several steps were taken to minimize the impact of unwanted temperature effects. Firstly, the input lasers were actively temperature- and current-controlled, and the output signal was found to vary in intensity by less than $5 \%$, both when measured before the sample and when passing through the DNH apertures before a trapping event. For the EAR experiments, after varying the wavelength by each wavelength step of $\sim 0.001 \mathrm{~nm}$, for each step, a wait time of $5 \mathrm{~s}$ was given to allow the system to stabilize before beginning data acquisition. In addition, any short-term fluctuations in signal due to temperature variation would be averaged out over the measurement time of $15 \mathrm{~s}$ per step. Moreover, the full frequency range was swept multiple times for each sample type, giving consistent results for each scan as seen in Figure 2d, which is a good indication that any potential long-term temperature drift did not introduce any variation in the measurements. The EAR measurement actually directly measures fluctuations of the laser transmission signal, which are a manifestation of localized heating effects of the interfering lasers coupling with the sample material. No peaks or signal drift were observed in measurements of background noise levels when EAR measurements were taken for the system with nothing trapped-just a DNH aperture with water. If there were temperature-induced artefacts from heating of the $\mathrm{DNH}$ apertures, they would be expected to be observed in these background measurements as well.

It is noted that recent works investigated temperature effects in this geometry and found that the temperature increase is of the order of $1-10 \mathrm{~K}$ due to heating with the laser $[82,83]$. In some cases, this can be beneficial because it elevates the room temperature experiment to physiological conditions. In the past, we attempted to control the temperature by having a heater and thermocouple on the stage; however, this led to optical drift and, thus, we did not attempt that approach in this work.

Much investigation has gone into determining elastic properties of viruses and, in particular, the vibrational frequencies of their structures in past works. Here, an easy-to-implement technique was presented to directly and unambiguously measure such frequencies for individual viral particles experimentally. This is in contrast to optical scattering methods for probing acoustic modes, such as Brillouin scattering which is generally performed on ensembles of particles. In addition, since the EAR technique does not rely on detection of angular dependence of forward-scattered laser light, the technique does not suffer from a frequency limit of a scattering angle around the zero-loss laser line. The vibrational frequency measured in this work for PhiX174 was found to be $32 \mathrm{GHz}$, which can be associated with the $\mathrm{L} 0$ mode predicted from elastic theory at $30 \mathrm{GHz}$. This predicted value relies on best estimates from previous works of longitudinal and transverse wave speeds of $1800 \mathrm{~m} / \mathrm{s}$ and $900 \mathrm{~m} / \mathrm{s}$, respectively. 
Excitation of viruses at their characteristic frequencies, once experimentally determined, may be useful for the selective destruction of the virus in question, as proposed in other studies [49-52]. This is a good direction for future work, as it would be a simple matter to excite the virus with the same interfering laser wavelengths, but at higher powers such that the resonant excitation might be sufficient to disrupt the structure without affecting surrounding material.

Author Contributions: Conceptualization, J.B., K.S.W., and R.G.; methodology, R.G.; formal analysis, J.B. and Y.W.; investigation, J.B. and Y.W.; resources, R.G.; writing-original draft preparation, J.B.; writing-review and editing, R.G. and K.S.W.; visualization, J.B. and Y.W.; supervision, R.G. and K.S.W.; funding acquisition, K.S.W. and R.G. All authors have read and agreed to the published version of the manuscript.

Funding: This research was funded by the Research Grants Council of Hong Kong through grant number AoE/P-02/12 and by the Natural Sciences and Engineering Research Council of Canada through the Discovery Grant and Research Tools and Instruments Grant.

Conflicts of Interest: The authors declare no conflict of interest.

\section{References}

1. Ashkin, A. Acceleration and trapping of particles by radiation pressure. Phys. Rev. Lett. 1970, $24,156$. [CrossRef]

2. Ashkin, A.; Dziedzic, J.M. Optical trapping and manipulation of viruses and bacteria. Science 1987, 235, 1517-1520. [CrossRef]

3. Pang, Y.; Song, H.; Kim, J.H.; Hou, X.; Cheng, W. Optical trapping of individual human immunodeficiency viruses in culture fluid reveals heterogeneity with single-molecule resolution. Nat. Nanotechnol. 2014, 9, 624-630. [CrossRef]

4. Gordon, R. Nanostructured metals for light-based technologies. Nanotechnology 2019, 30, 212001. [CrossRef] [PubMed]

5. Rohrbach, A. Stiffness of optical traps: Quantitative agreement between experiment and electromagnetic theory. Phys. Rev. Lett. 2005, 95, 168102. [CrossRef] [PubMed]

6. Kotnala, A.; DePaoli, D.; Gordon, R. Sensing nanoparticles using a double nanohole optical trap. Lab Chip 2013, 13, 4142-4146. [CrossRef] [PubMed]

7. Kotnala, A.; Gordon, R. Quantification of high-efficiency trapping of nanoparticles in a double nanohole optical tweezer. Nano Lett. 2014, 14, 853-856. [CrossRef]

8. $\quad \mathrm{Xu}, \mathrm{H}$.; Jones, S.; Choi, B.-C.; Gordon, R. Characterization of individual magnetic nanoparticles in solution by double nanohole optical tweezers. Nano Lett. 2016, 16, 2639-2643. [CrossRef]

9. Wheaton, S.; Gelfand, R.M.; Gordon, R. Probing the Raman-active acoustic vibrations of nanoparticles with extraordinary spectral resolution. Nat. Photonics 2015, 9, 68-72. [CrossRef]

10. Kotnala, A.; Wheaton, S.; Gordon, R. Playing the notes of DNA with light: Extremely high frequency nanomechanical oscillations. Nanoscale 2015, 7, 2295-2300. [CrossRef]

11. Al Balushi, A.A.; Zehtabi-Oskuie, A.; Gordon, R. Observing single protein binding by optical transmission through a double nanohole aperture in a metal film. Biomed. Opt. Express 2013, 4, 1504-1511. [CrossRef] [PubMed]

12. Novotny, L.; Bian, R.X.; Xie, X.S. Theory of nanometric optical tweezers. Phys. Rev. Lett. 1997, $79,645$. [CrossRef]

13. Chaumet, P.C.; Rahmani, A.; Nieto-Vesperinas, M. Optical trapping and manipulation of nano-objects with an apertureless probe. Phys. Rev. Lett. 2002, 88, 123601. [CrossRef] [PubMed]

14. Nieto-Vesperinas, M.; Chaumet, P.; Rahmani, A. Near-field photonic forces. Philos. Trans.-R. Soc. Lond. Ser. A Math. Phys. Eng. Sci. 2004, 362, 719-738. [CrossRef] [PubMed]

15. Kwak, E.-S.; Onuta, T.-D.; Amarie, D.; Potyrailo, R.; Stein, B.; Jacobson, S.C.; Schaich, W.; Dragnea, B. Optical trapping with integrated near-field apertures. J. Phys. Chem. B 2004, 108, 13607-13612. [CrossRef]

16. Juan, M.L.; Gordon, R.; Pang, Y.; Eftekhari, F.; Quidant, R. Self-induced back-action optical trapping of dielectric nanoparticles. Nat. Phys. 2009, 5, 915-919. [CrossRef]

17. Neuman, K.C.; Block, S.M. Optical trapping. Rev. Sci. Instrum. 2004, 75, 2787-2809. [CrossRef]

18. Juan, M.L.; Righini, M.; Quidant, R. Plasmon nano-optical tweezers. Nat. Photonics 2011, 5, 349-356. [CrossRef] 
19. Pang, Y.; Gordon, R. Optical trapping of $12 \mathrm{~nm}$ dielectric spheres using double-nanoholes in a gold film. Nano Lett. 2011, 11, 3763-3767. [CrossRef]

20. Pang, Y.; Gordon, R. Nanophotonics using a subwavelength aperture in a metal film. Nanotechnol. Rev. 2012, 1, 339-362. [CrossRef]

21. Gordon, R. Biosensing with nanoaperture optical tweezers. Opt. Laser Technol. 2019, 109, 328-335. [CrossRef]

22. Al Balushi, A.A.; Kotnala, A.; Wheaton, S.; Gelfand, R.M.; Rajashekara, Y.; Gordon, R. Label-free free-solution nanoaperture optical tweezers for single molecule protein studies. Analyst 2015, 140, 4760-4778. [CrossRef] [PubMed]

23. Tolić-Nørrelykke, S.F.; Schäffer, E.; Howard, J.; Pavone, F.S.; Jülicher, F.; Flyvbjerg, H. Calibration of optical tweezers with positional detection in the back focal plane. Rev. Sci. Instrum. 2006, 77, 103101. [CrossRef]

24. Ashkin, A. Optical trapping and manipulation of neutral particles using lasers. Proc. Natl. Acad. Sci. USA 1997, 94, 4853-4860. [CrossRef]

25. Ashkin, A. History of optical trapping and manipulation of small-neutral particle, atoms, and molecules. IEEE J. Sel. Top. Quantum Electron. 2000, 6, 841-856. [CrossRef]

26. Pang, Y.; Gordon, R. Optical trapping of a single protein. Nano Lett. 2011, 12, 402-406. [CrossRef]

27. Pang, Y.; Song, H.; Cheng, W. Using optical trap to measure the refractive index of a single animal virus in culture fluid with high precision. Biomed. Opt. Express 2016, 7, 1672-1689. [CrossRef]

28. Padgett, M.; Di Leonardo, R. Holographic optical tweezers and their relevance to lab on chip devices. Lab Chip 2011, 11, 1196-1205. [CrossRef]

29. Pagliara, S.; Dettmer, S.L.; Keyser, U.F. Channel-facilitated diffusion boosted by particle binding at the channel entrance. Phys. Rev. Lett. 2014, 113, 048102. [CrossRef]

30. Padgett, M.; Bowman, R. Tweezers with a twist. Nat. Photonics 2011, 5, 343-348. [CrossRef]

31. Locatelli, E.; Pierno, M.; Baldovin, F.; Orlandini, E.; Tan, Y.; Pagliara, S. Single-file escape of colloidal particles from microfluidic channels. Phys. Rev. Lett. 2016, 117, 038001. [CrossRef] [PubMed]

32. Aggarwal, A. Determination of prestress and elastic properties of virus capsids. Phys. Rev. E 2018, $97,032414$. [CrossRef] [PubMed]

33. Christianto, V.; Smarandache, F. Modeling virus as elastic sphere in Newtonian fluid based on $3 \mathrm{~d}$ Navier-Stokes equations. J. Nanosci. Nanomed. 2018, 2,1-2.

34. May, E.R.; Brooks, C.L., III. Determination of viral capsid elastic properties from equilibrium thermal fluctuations. Phys. Rev. Lett. 2011, 106, 188101. [CrossRef]

35. Robach, Y.; Michels, B.; Cerf, R.; Braunwald, J.; Tripier-Darcy, F. Ultrasonic absorption evidence for structural fluctuations in frog virus 3 and its subparticles. Proc. Natl. Acad. Sci. USA 1983, 80, 3981-3985. [CrossRef]

36. May, E.R.; Aggarwal, A.; Klug, W.S.; Brooks, C.L., III. Viral capsid equilibrium dynamics reveals nonuniform elastic properties. Biophys. J. 2011, 100, L59-L61. [CrossRef]

37. Ford, L. Estimate of the vibrational frequencies of spherical virus particles. Phys. Rev. E 2003, 67, 051924. [CrossRef]

38. Saviot, L.; Murray, D.B.; Mermet, A.; Duval, E. Comment on "Estimate of the vibrational frequencies of spherical virus particles". Phys. Rev. E 2004, 69, 023901. [CrossRef]

39. Saviot, L.; Netting, C.H.; Murray, D.B. Damping by bulk and shear viscosity of confined acoustic phonons for nanostructures in aqueous solution. J. Phys. Chem. B 2007, 111, 7457-7461. [CrossRef]

40. Fonoberov, V.A.; Balandin, A.A. Low-frequency vibrational modes of viruses used for nanoelectronic self-assemblies. Phys. Status Solidi (b) 2004, 241, R67-R69. [CrossRef]

41. Balandin, A.A.; Fonoberov, V.A. Vibrational modes of nano-template viruses. J. Biomed. Nanotechnol. 2005, 1, 90-95. [CrossRef]

42. Tsen, K.-T.; Dykeman, E.C.; Sankey, O.F.; Tsen, S.-W.D.; Lin, N.-T.; Kiang, J.G. Raman scattering studies of the low-frequency vibrational modes of bacteriophage M13 in water-observation of an axial torsion mode. Nanotechnology 2006, 17, 5474. [CrossRef]

43. Stephanidis, B.; Adichtchev, S.; Gouet, P.; McPherson, A.; Mermet, A. Elastic properties of viruses. Biophys. J. 2007, 93, 1354-1359. [CrossRef] [PubMed]

44. Talati, M.; Jha, P.K. Acoustic phonon quantization and low-frequency Raman spectra of spherical viruses. Phys. Rev. E 2006, 73, 011901. [CrossRef] [PubMed]

45. Dykeman, E.C.; Sankey, O.F. Low frequency mechanical modes of viral capsids: An atomistic approach. Phys. Rev. Lett. 2008, 100, 028101. [CrossRef] [PubMed] 
46. Hartschuh, R.; Wargacki, S.; Xiong, H.; Neiswinger, J.; Kisliuk, A.; Sihn, S.; Ward, V.; Vaia, R.; Sokolov, A. How rigid are viruses. Phys. Rev. E 2008, 78, 021907. [CrossRef] [PubMed]

47. Liu, T.-M.; Chen, H.-P.; Wang, L.-T.; Wang, J.-R.; Luo, T.-N.; Chen, Y.-J.; Liu, S.-I.; Sun, C.-K. Microwave resonant absorption of viruses through dipolar coupling with confined acoustic vibrations. Appl. Phys. Lett. 2009, 94, 043902. [CrossRef]

48. Tcherniega, N.; Pershin, S.; Bunkin, A.; Donchenko, E.; Karpova, O.; Kudryavtseva, A.; Lednev, V.; Mironova, T.; Shevchenko, M.; Strokov, M.; et al. Laser excitation of gigahertz vibrations in Cauliflower mosaic viruses' suspension. Laser Phys. Lett. 2018, 15, 095603. [CrossRef]

49. Babincová, M.; Sourivong, P.; Babinec, P. Resonant absorption of ultrasound energy as a method of HIV destruction. Med. Hypotheses 2000, 55, 450. [CrossRef]

50. Tsen, S.-W.D.; Kingsley, D.H.; Poweleit, C.; Achilefu, S.; Soroka, D.S.; Wu, T.C.; Tsen, K.-T. Studies of inactivation mechanism of non-enveloped icosahedral virus by a visible ultrashort pulsed laser. Virol. J. 2014, 11, 20. [CrossRef]

51. Yang, S.-C.; Lin, H.-C.; Liu, T.-M.; Lu, J.-T.; Hung, W.-T.; Huang, Y.-R.; Tsai, Y.-C.; Kao, C.-L.; Chen, S.-Y.; Sun, C.-K. Efficient structure resonance energy transfer from microwaves to confined acoustic vibrations in viruses. Sci. Rep. 2015, 5, 18030. [CrossRef] [PubMed]

52. Chrysikopoulos, C.V.; Manariotis, I.D.; Syngouna, V.I. Virus inactivation by high frequency ultrasound in combination with visible light. Colloids Surf. B Biointerfaces 2013, 107, 174-179. [CrossRef] [PubMed]

53. Yadav, H.K.; Gupta, V.; Sreenivas, K.; Singh, S.; Sundarakannan, B.; Katiyar, R. Low frequency Raman scattering from acoustic phonons confined in ZnO nanoparticles. Phys. Rev. Lett. 2006, 97, 085502. [CrossRef] [PubMed]

54. Van Thourhout, D.; Roels, J. Optomechanical device actuation through the optical gradient force. Nat. Photonics 2010, 4, 211. [CrossRef]

55. Lamb, H. On the vibrations of an elastic sphere. Proc. Lond. Math. Soc. 1881, 1, 189-212. [CrossRef]

56. Saviot, L.; Champagnon, B.; Duval, E.; Kudriavtsev, I.; Ekimov, A. Size dependence of acoustic and optical vibrational modes of CdSe nanocrystals in glasses. J. Non-Cryst. Solids 1996, 197, 238-246. [CrossRef]

57. Murray, D.B.; Saviot, L. Phonons in an inhomogeneous continuum: Vibrations of an embedded nanoparticle. Phys. Rev. B 2004, 69, 094305. [CrossRef]

58. Sadd, M.H. Elasticity: Theory, Applications, and Numerics; Academic Press: Cambridge, MA, USA, 2009.

59. Sirotkin, S.; Mermet, A.; Bergoin, M.; Ward, V.; Van Etten, J.L. Viruses as nanoparticles: Structure versus collective dynamics. Phys. Rev. E 2014, 90, 022718. [CrossRef]

60. Donchenko, E.; Karpova, O.; Kudryavtseva, A.; Pershin, S.; Savichev, V.; Strokov, M.; Tcherniega, N.; Zemskov, K. Stimulated low-frequency Raman scattering in plant virus suspensions. In Proceedings of the Journal of Physics Conference Series, Moscow, Russia, 25-27 January 2017; Volume 918.

61. Hamrick, P.E.; Cleary, S.F. Laser-induced acoustic breakage of tobacco mosaic virus. Nature 1968, 220,909-910. [CrossRef]

62. Ivanovska, I.; De Pablo, P.; Ibarra, B.; Sgalari, G.; MacKintosh, F.; Carrascosa, J.; Schmidt, C.; Wuite, G. Bacteriophage capsids: Tough nanoshells with complex elastic properties. Proc. Natl. Acad. Sci. USA 2004, 101, 7600-7605. [CrossRef]

63. Krishnamani, V.; Globisch, C.; Peter, C.; Deserno, M. Breaking a Virus: Identifying Molecular Level Failure Modes of Viral Capsid Compression through Multi-Scale Simulation Techniques. Biophys. J. 2014, 106, 61a-62a. [CrossRef]

64. Lee, B.H.; Jo, S.; Choi, M.; Kim, M.H.; Choi, J.B.; Kim, M.K. Normal mode analysis of Zika virus. Comput. Biol. Chem. 2018, 72, 53-61. [CrossRef] [PubMed]

65. Lodish, H.; Berk, A.; Zipursky, S.L.; Matsudaira, P.; Baltimore, D.; Darnell, J. Viruses: Structure, function, and uses. In Molecular Cell Biology, 4th ed.; WH Freeman: New York, NY, USA, 2000.

66. Marchetti, M.; Wuite, G.; Roos, W. Atomic force microscopy observation and characterization of single virions and virus-like particles by nano-indentation. Curr. Opin. Virol. 2016, 18, 82-88. [CrossRef] [PubMed]

67. Roos, W.; Gibbons, M.; Arkhipov, A.; Uetrecht, C.; Watts, N.; Wingfield, P.; Steven, A.; Heck, A.; Schulten, K.; Klug, W.; et al. Squeezing protein shells: How continuum elastic models, molecular dynamics simulations, and experiments coalesce at the nanoscale. Biophys. J. 2010, 99, 1175-1181. [CrossRef] 
68. Caspar, D.L.; Klug, A. Physical principles in the construction of regular viruses. In Proceedings of the Cold Spring Harbor Symposia on Quantitative Biology; Cold Spring Harbor Laboratory Press: Cold Spring Harbor, NY, USA, 1962; Volume 27, pp. 1-24.

69. Vernizzi, G.; Sknepnek, R.; De La Cruz, M.O. Platonic and Archimedean geometries in multicomponent elastic membranes. Proc. Natl. Acad. Sci. USA 2011, 108, 4292-4296. [CrossRef]

70. Prasad, B.V.; Schmid, M.F. Principles of virus structural organization. In Viral Molecular Machines; Springer: New York, NY, USA, 2012; pp. 17-47.

71. Tromans, W.; Horne, R. The structure of bacteriophage $\phi X 174$. Virology 1961, 15, 1-7. [CrossRef]

72. Kazumori, Y. Electron microscopic studies of bacteriophage $\phi$ X174 intact and 'eclipsing'particles, and the genome by the staining and shadowing method. J. Virol. Methods 1981, 2, 159-167. [CrossRef]

73. Olson, N.H.; Baker, T.S.; Willingmann, P.; Incardona, N.L. The Three-Dimensional Structure of Frozen-Hydrated Bacteriophage фX174. J. Struct. Biol. 1992, 108, 168-175. [CrossRef]

74. McKenna, R.; Ilag, L.L.; Rossmann, M.G. Analysis of the Single-stranded DNA Bacteriophage $\phi X 174$, Refined at a Resolution of 3. $0 \backslash$ AA. J. Mol. Biol. 1994, 237, 517-543. [CrossRef]

75. Michel, A.; Clermont, O.; Denamur, E.; Tenaillon, O. Bacteriophage PhiX174's ecological niche and the flexibility of its Escherichia coli lipopolysaccharide receptor. Appl. Environ. Microbiol. 2010, 76, 7310-7313. [CrossRef]

76. Bosch, A. Human enteric viruses in the water environment: A minireview. Int. Microbiol. 1998, 1, $191-196$. [PubMed]

77. Bhamla, M.S.; Benson, B.; Chai, C.; Katsikis, G.; Johri, A.; Prakash, M. Hand-powered ultralow-cost paper centrifuge. Nat. Biomed. Eng. 2017, 1, 0009. [CrossRef]

78. Cialla, D.; Deckert-Gaudig, T.; Budich, C.; Laue, M.; Möller, R.; Naumann, D.; Deckert, V.; Popp, J. Raman to the limit: Tip-enhanced Raman spectroscopic investigations of a single tobacco mosaic virus. J. Raman Spectrosc. 2009, 40, 240-243. [CrossRef]

79. Driskell, J.D.; Zhu, Y.; Kirkwood, C.D.; Zhao, Y.; Dluhy, R.A.; Tripp, R.A. Rapid and sensitive detection of rotavirus molecular signatures using surface enhanced Raman spectroscopy. PLoS ONE 2010, 5, e10222. [CrossRef]

80. Jones, S.; Al Balushi, A.A.; Gordon, R. Raman spectroscopy of single nanoparticles in a double-nanohole optical tweezer system. J. Opt. 2015, 17, 102001. [CrossRef]

81. Moor, K.; Terada, Y.; Taketani, A.; Hiroko, M.; Ohtani, K.; Sato, H. Early detection of virus infection in live human cells using Raman spectroscopy. J. Biomed. Opt. 2018, 23, 097001. [CrossRef]

82. Jiang, Q.; Rogez, B.; Claude, J.B.; Baffou, G.; Wenger, J. Temperature Measurement in Plasmonic Nanoapertures used for Optical Trapping. ACS Photonics 2019, 6, 1763-1773. [CrossRef]

83. Verschueren, D.V.; Pud, S.; Shi, X.; De Angelis, L.; Kuipers, L.; Dekker, C. Label-Free Optical Detection of DNA Translocations Through Plasmonic Nanopores. ACS Nano 2018, 13, 61-70. [CrossRef] 